\title{
Aesthetic Experience: Is it Viable in Contemporary Education?
}

\section{Anne Wolcott}

\begin{abstract}
Margaret Harrison's Rape, (1979) consists of oil paint and collage which combines images, texts, and represented objects. There is a frieze across the top of the image of copies of famous paintings usually considered "high culture": The Three Graces by Rubens, Ruggerio Rescuing Angelica by Ingres, St. George and Princess Sabra by Rosetti, and The Luncheon on the Grass by Manet. The fine art images are juxtaposed with a contemporary advertisement which displays the body of a woman, equating it in the caption with juicy, tasty food. In contrast to these visions of the woman are painted representations of some common instruments of rape -- knives, scissors, broken bottles, and razors -- which visually threaten the bodies displayed above. Between these two visual discourses Harrison has placed press cuttings in whose reports of rape trials the complicity of the legal profession with violence against women and with the myth of "women ask for it" (sanctioned by high culture as in the paintings above) is forcefully catalogued. As observers of this piece how should we respond? Should we respond aesthetically or morally to the work? Can we distinguish between the two? Should we? Does the idea of aesthetic experience make sense in the context of contemporary art? What are the implications of these questions for art education? Is the concept of aesthetic experience viable in contemporary art education?
\end{abstract}

Beginning in the eighteenth century theorists attempted to define and explain the concept of aesthetic experience. Aesthetic experience has been analyzed and discussed in terms of whether it is an emotional and/or intellectual experience, whether particular emotions are inherent in the experience, whether an experience is coherent, unified or fulfilling and in what way, whether its affects are immediate or delayed, and what properties a work of art must have in order to be aesthetically experienced.

Aesthetics had its beginnings in the speculations of the Greeks on the nature of things and ideas. At one time it was said that philosophers were dedicated to the pursuit of the true, the good, and the beautiful, the possession of which made for the wholeness of man (Kaelin, 1989). The field of aesthetics developed out of two concerns, both discussed by Plato: the theory of beauty and the theory of art. Philosophers have continued the debate about the theory of art much in the same way as Plato, but the theory of beauty has undergone drastic changes since Plato's time. Prior to the eighteenth century philosophers generally assumed that "beauty" could be named as an objective property of things, either as a transcendental or empirical property, depending on the theory (Dickie, 1971). In the eighteenth

Working Papers in Art Education 1989 - 1990 
century philosophers came to believe that beauty was no longer the ideal pursuit of the philosopher. Whereas earlier philosophers had discussed only the nature of beauty, eighteenth-century thinkers became interested in other concepts. During this time British philosophers introduced the philosophy of taste and by the middle of the century the term "aesthetics" had replaced the theory of beauty. The concept of beauty became synonymous with "having aesthetic value" or as an aesthetic adjective on the same level as "sublime" and "picturesque." The shift of attention began to focus on human nature and its relationship to the objective world and the faculty of taste was presented as the basis for objective judgement. Philosophy became subjectized, attention was turned in on the subject, the subject's mind, and his mental faculties. Other notions such as the sublime and the picturesque were also included in aesthetic theory; creating a richer and more adequate theory and at the same time fragmenting it. Thus the tension set up by this fragmentation of the theory of beauty led to the emergence of the concept of the aesthetic. Aesthetic theories united the problems of the theory of beauty and the philosophy of taste and were worked out by several philosophers, most notably Immanuel Kant.

Kant turned the course of philosophy in new directions by providing a theory of aesthetic judgement or taste which would give an adequate analysis of the experience of the beautiful, the sublime, and related phenomena as they occur in art and nature (Dickie, 1971). According to Kant, the judgement of taste is characterized by two distinctions; aesthetic judgements which are subjective judgements about pleasure and pain and logical judgements which refer to an object and its properties. Kant contended that art experiences were "aesthetic" rather than logical; the imagination functions first to form a series of impressions of sense, which are then related by judgement to a concept not given to the understanding, because prior to the formation of object the concept does not exist. In logical, or cognitive judgements the relationship is reversed (Kaelin, 1989). The distinguishing feature of the judgement of taste is that the satisfaction reported is "disinterested." Disinterestedness is primarily involved with the experiencing subject, who focuses on the object of appreciation; the form of purpose. Consequently, it is the recognition of the form of purpose, and the purpose itself, which evokes the beauty experience. The form of a work of art could be the design of a painting or the composition of a musical piece, both purposive activities of the human agent. Thus, the notions of disinterestedness and focusing on formal relations became part of philosophers' analysis and concept of the aesthetic. Kant's theory can be seen as having elements of both earlier and later theories, serving as a link between the two centuries. By the end of the eighteenth century, the concept of taste had been exhausted and had paved the way for the nineteenth century concept of the aesthetic (Dickie, 1971).

Since the nineteenth century, the subject matter of aesthetics was the philosophy of the aesthetic, replacing the theory of beauty, and the philosophy of art. Philosophers have attempted to define the aesthetic value of art and in doing so, have provided insights and explanations of their

Working Papers in Art Education 1989 - 1990 
theories that have formed the basis of interpretation of the arts for several decades. Philosophers began developing the notion of aesthetic attitude and the idea that any object, artificial or natural, can become an aesthetic object if a person directs an aesthetic attitude toward that object. Thereby making the aesthetic object the focus or cause of aesthetic experience and the proper object of appreciation (Dickie, 1971). Ideas concerning aesthetic experience and its conditions increasingly shifted attention toward one's experience of art.

Theorists such as John Dewey and Monroe Beardsley followed in the footsteps of previous philosophers, not only reiterating several basic tenets of their theories, but developing more fully the concept of aesthetic experience. What makes these philosophers noteworthy is their exemplary explications of aesthetic experience and its significance to art. Each in his own way has attempted to define aesthetic experience and their theories have strongly influenced the interpretation/understanding of works of art; in the field of aesthetics and art education.

John Dewey is probably best known to art educators for his book Art as Experience, first published in 1934, in which he set forth a theory of art based on ones' experience of art. Art as Experience is especially illuminating in its descriptions of structure and ramifications of art and aesthetic experience. Dewey presents an analysis of aesthetic experience within the context of our ordinary lives and also presents an analysis of elements such as: emotion, expression, form, and rhythm. Dewey's dominant theme is that of experience; experience is the way in which humans interact with their environment which is envolved in the very process of living. Experience occurs in and through nature. He believed that the task of the philosophy of art was "to restore continuity between the refined and intensified forms of experience that are works of art and the everyday events, doings, and sufferings that are universally recognized to constitute experience" (p. 3). Then humans will attain fulfillment and the highest form of this fulfillment is through artistic or aesthetic experience.

In grouping together aestheticians who have written a good deal about aesthetic experience we must also look at Monroe Beardsley who has used the term repeatedly in a lot of his writings. Since the publication of his book entitled Aesthetics: Problems in the Philosophy of Criticism (1958), the concept of aesthetic experience has been central to his aesthetics. In the 1968 presidential address to the American Society for Aesthetics and its subsequent publication in 1969, "Aesthetic Experience Regained" is an attempt in Beardsley's words, "to rejuvenate the concept that has played an important role in twentieth century aesthetics" (p. 3). As he noted in a later publication entitled The Aesthetic Point of View: Selected Essays, Monroe C. Beardsley (1982), some of his fundamental views have remained the same and some have "necessary improvements," but still hold up under critical scrutiny.

Working Papers in Art Education 1989 - 1990 
Beginning with ideas in Aesthetics (1958), Beardsley's concern is whether we can isolate and describe in general terms, certain features of experience that are peculiarly characteristic of our experience with aesthetic objects. He notes that certain generalizations have already been obtained by acute introspection of previous writers such as: Immanuel Kant, John Dewey, and Edward Bullough.

In his article "Aesthetic Experience Regained" (1969), Beardsley continues with the question, what does it mean to say someone is having an aesthetic experience? He asserts that an aesthetic experience can have a certain duration but what else can be said about it? Although admitting uneasiness about proposing an answer, Beardsley states,

that a person is having an aesthetic experience during a particular stretch of time if and only if the greater part of his mental activity during that time is united and made pleasurable by being tied to the form and qualities of a sensuously presented or imaginatively intended object on which his primary attention is concentrated (p. 5).

Thus, such theorists as John Dewey and Monroe Beardsley concerned themselves with the definition, limitations, and explanation of aesthetic experience. Their theories were based on the ideas that aesthetic experience was a certain way of responding to works of art, that generally had to do with an "intuited," immediately perceived form in the work of art.

Proponents of aesthetic experience shared the idea that although we may have various degrees and kinds of experiences; aesthetic experience is qualified as being more intense, coherent, and having a sense of unity or wholeness which gives us pleasure or enjoyment when we encounter works of art. The perceiver as well as the artist must order the elements of the whole that is in the form. Perception is not a passive activity; like the artist, one must select, simplify, clarify, and condense according to one's interest. The work of art is the actual experiencing of it, its different elements and specific qualities are blended and fused together in a way physical things cannot emulate. To be truly an aesthetic experience there must be a consummatory aspect and a sense of wholeness. Combinations of art's inherent qualities: lines, colors, shapes, can elicit and aesthetic response or experience. These theorists believed that when we examine a work of art, we must examine it as a whole unit or form and not refer to external references for meaning or experience.

During the Modernist period in art these aesthetic theories were often used to interpret the ever changing objects of art. The art of this period can best be characterized by its rapidly changing styles. Modernism was predicated on the invention of personal style and innovation; artists had greater autonomy and personal expression. Form was emphasized over content; ignoring subject matter, narrative, and representation. Therefore, during the Modernist period an aesthetic experience evoked by the visual 
form was believed to be the value of art. The insights and explanatory usefulness of these theories are well-known and have formed the basis of interpretation of the arts for several decades. The ideas concerning aesthetic experience and its conditions increasingly shifted attention toward one's experience of art.

Concomitantly in the field of art education the theories of John Dewey and Monroe Beardsley were having a great deal of influence on art educators, most notably Ralph Smith and Elliott Eisner. Their writings often cited and expressed the basic tenets of Dewey's and Beardsley's philosophies which in turn influenced the theories and practices in the field of art education. Thus, during the Modernist era, came the evolution in the field of art education of interpreting works of art through their formal and sensual elements and how interpretations made one "feel." The interpretation of art was often confined to formal analysis of works of art and one's experience of this analysis.

Postmodernism, the term given to the year in which we now exist is thought to have originated in the 1970s. Postmodernism is still evolving, as are the theories of art and criticism. Art has become critical, critiquing both culture and society. During this era of pluralism it has become difficult to define quality and value in art. Works of art have become a means of discourse: art contemplating art, politics, society, religion, or culture. Today, the work of art must be looked at as a document: what does it have to say?

The art of the present is situated at a crossroads, of institutions of art and political economy, of representations of sexual identity and social life. Its primary concern is not with the traditional or modernist proprieties of art, with refinement of style or innovation of form, aesthetic sublimity or ontological reflection on art as such. This work does not bracket art for formal or perceptual experiment but rather seeks out its affiliations with other practices (Foster, 1985). Artists have shifted their positions; the artist has become a manipulator of signs more than a producer of art objects, and the viewer an active reader of messages rather than a passive contemplator of the aesthetic. The theoretical redefinition of the artifact might be seen as a transition from modernist "work" to postmodernist "text." 'Work' suggests an aesthetic, symbolic whole sealed by an origin (i.e., author) and 'text' suggests an aaesthetic, 'multidimensional space in which a variety of writings, none of them original, blend and clash'" (p. 129)

Works of art by such artists as Hans Haacke, Nancy Spero, Allan McCollum, and Daniel Bruen focus primarily on a dialogue with our society. As Hal Foster points out, postmodernist art is not concerned with the traditional formal purity of artistic mediums, but with textual "impurity" -- the interconnections of power and knowledge in social representations.

At the same time, contemporary art education is undergoing a reform in which it is attempting to focus on a more rigorous academic, skills and content-based curriculum. This new, broader conception of art education 
known as discipline-based art education, incorporates the four disciplines of art production, art history, art criticism, and aesthetics. By including the four disciplines of art, the art education curriculum will provide students with more content, concepts, techniques, and general information, thus contributing to a greater knowledge of art and the world. Some forms of DBAE will present works of art as central to the curriculum content, allowing students to develop the concepts they learn from the various disciplines. The aim of DBAE is to develop students' abilities to understand and appreciate art; to be able to discuss and evaluate unfamiliar and unusual works of art, including contemporary works of art. As in the contemporary art world, the construction of meaning in works of art is the major issue.

How then do the theories of aesthetic experience fit into the new context of art education? At one point in art education, discussing the formal elements of a work of art and how it made one "feel" was the extent of interpretation. Works of art were experienced through their formal and sensual qualities, never going much beyond one's initial perception/experience of the work of art. Today, the interpretation of meaning is of primary importance. The ideas of postmodern art and art education indicate the modernist conception of aesthetic experience has been called into question. No longer do works of art exist solely for the sake of our experience of them, artists are creating a discourse; critiquing society and culture through their art. There is a trend away from formal unity, a disjointedness created by the juxtaposition of images and texts. Does the modernist conception of aesthetic experience provide an adequate basis for interpreting contemporary works of art?

\section{References}

Beardsley, Monroe C. (1958). Aesthetics: Problems in the philosophy of criticism. New York: Harcourt, Brace \& World, Inc.

(1966). Aesthetics from classical Greece to the present.

Alabama: University of Alabama Press.

(1969). Aesthetic experience regained. Journal of Aesthetics and Art Criticism, 28, 3-11.

(1982). The aesthetic point of view. Ithaca: Cornell University Press.

Dewey, John. (1934). Art as experience. New York: G. P. Putnam's Sons.

Dickie, George (1971). Aesthetics: An introduction. New York: The Bobbs-Merrill Company, Inc.

Foster, Hal. (1983). The anti-aesthetic: Essays on postmodern culture. Port Townsend, Washington: Bay Press. 
Kaelin, E. F. (1989). An aesthetics for art educators. New York: Teachers College Press. 